\title{
FAILURE AFTER FUNDOPLICATION: RE-FUNDOPLICATION? IS THERE A ROOM FOR GASTRECTOMY? IN WHICH CLINICAL SCENARIES?
}

\author{
Falha após fundoplicatura: Re-fundoplicatura? Existe oportunidade para gastrectomia? Em quais cenários clínicos?
}

\author{
Italo BRAGHETTO'1, Attila CSENDES
}

How to cite this article: Braghetto I, Csendes A. Failure after fundoplication: re-fundoplication? Is there a room for gastrectomy? In which clinical scenaries? ABCD Arq Bras Cir Dig. 2019;32(2):e1440. DOI: /10.1590/0102-672020190001e1440

From the ${ }^{1}$ Department of Surgery, Hospital Clínico "Dr. José J. Aguirre", Faculty of Medicine, University of Chile, Santiago Chile.

HEADINGS - Gastroesophageal reflux Re-fundoplication. Barrett's esophagus. Obesity. Distal gastrectomy.
ABSTRACT - Background: Re-fundoplication is the most often procedure performed after failed fundoplication, but re-failure is even higher. Aim: The objectives are: a) to discuss the results of fundoplication and re-fundoplication in these cases, and b) to analyze in which clinical situation there is a room for gastrectomy after failed fundoplication. Method: This experience includes 104 patients submitted to re-fundoplication after failure of the initial operation, 50 cases of long segment Barrett's esophagus and 60 patients with morbid obesity, comparing the postoperative outcome in terms of clinical, endoscopic, manometric and $24 \mathrm{~h} \mathrm{pH}$ monitoring results. Results: In patients with failure after initial fundoplication, redo-fundoplication shows the worst clinical results (symptoms, endoscopic esophagitis, manometry and $24 \mathrm{~h} \mathrm{pH}$ monitoring). In patients with long segment Barrett's esophagus, better results were observed after fundoplication plus Roux-en-Y distal gastrectomy and in obese patients similar results regarding symptoms, endoscopic esophagitis and $24 \mathrm{~h} \mathrm{pH}$ monitoring were observed after both fundoplication plus distal gastrectomy or laparoscopic resectional gastric bypass, while regarding manometry, normal LES pressure was observed only after fundoplication plus distal gastrectomy. Conclusion: Distal gastrectomy is recommended for patients with failure after initial fundoplication, patients with long segment Barrett's esophagus and obese patients with gastroesophageal reflux disease and Barrett's esophagus. Despite its higher morbidity, this procedure represents an important addition to the surgical armamentarium.

\section{Correspondence: \\ Italo Braghetto \\ E-mail: ibraghet@hcuch.cl \\ Financial source: none \\ Conflict of interest: none}

Received for publication: 15/01/2019 Accepted for publication: 21/02/2019

DESCRITORES - Refluxo gastroesofágico. Re-fundoplicatura. Esôfago de Barrett. Obesidade. Gastrectomia distal.
RESUMO - Racional: Re-fundoplicatura é o procedimento mais frequentemente realizado após falha na fundoplicatura, mas neste caso a falha é ainda maior. Objetivo: a) discutir os resultados da fundoplicatura e re-fundoplicatura nesses casos; e b) analisar em que situação clínica há espaço para gastrectomia após falha na fundoplicatura. Método: Esta experiência inclui 104 pacientes submetidos à re-fundoplicatura após falha da operação inicial, sendo 50 casos de esôfago de Barrett de segmento longo e 60 pacientes com obesidade mórbida, comparandose o resultado pós-operatório em termos de pH clínico, endoscópico, manométrico de 24 h de monitoramento. Resultados: Em pacientes com falha após a fundoplicatura inicial, a re-fundoplicatura mostra os piores resultados clínicos (sintomas, esofagite endoscópica, manometria e pHmetria 24 h). Em pacientes com esôfago de Barrett de segmento longo, melhores resultados foram observados após fundoplicatura com gastrectomia distal em Y-de-Roux e em pacientes obesos resultados semelhantes em relação aos sintomas, esofagite endoscópica e monitoramento de $\mathrm{pH} 24 \mathrm{~h}$ foram observados após fundoplicatura com gastrectomia distal ou ressecção com bypass gástrico laparoscópico, enquanto que em relação à manometria, a pressão normal do EEI só foi observada após a fundoplicatura e gastrectomia distal. Conclusão: A gastrectomia distal é recomendada para pacientes com falha após a fundoplicatura inicial, pacientes com esôfago de Barrett de segmento longo e obesos com doença do refluxo gastroesofágico e esôfago de Barrett. Apesar de sua maior morbidade, esse procedimento representa um importante acréscimo ao arsenal cirúrgico.

\section{INTRODUCTION}

$\mathrm{T}$ otal or partial fundoplication, are the current surgical treatments for gastroesophageal reflux disease (GERD). However, there are circumstances in which the procedure fails due to an incorrect or incomplete preoperative evaluation, technical factors or the patients' characteristics. Therefore, it is necessary to find the best technique in order to assure the best long term outcome after this operation.

There are three clinical situations in which fundoplication fails: 1) recurrent disease after failed fundoplication; 2) in Barrett's esophagus; 3 ) in obese.

The mean reported failure after fundoplication is nearly $18 \%$ (3-33\%) associated with recurrent reflux symptoms or erosive esophagitis, and $4.5-20 \%$ of these patients need re-operation ${ }^{5,20,21,29,51,52}$. The reported failure in non-Barrett's patients is $5-12 \%$ and in Barrett's failure is observed three times more frequently, from 12 to $39 \%$. The 
recurrence of symptoms due to failed fundoplication reaches $31.3 \%$ in obese ${ }^{24}$. Patients with BE have more incompetent lower esophageal sphincter (LES), severe anatomic distortions, greater amount of acid and bile reflux and severe damage of distal esophagus. Therefore, fundoplication becomes more difficult and complex and it is associated with a high rate of failure.

The main reasons for failure are esophageal dysmotility and delayed clearance associated with physiologic alterations of the LES. Other reasons are secondary to the surgical technique performed such as the absence of clear anatomical landmarks, anatomical deformities due to dilated cardia, presence of a hiatal hernia or complicated long segment Barrett's esophagus (LSBE) or obesity. These can provoke surgical difficulties during the procedure conducing to abnormal primary repair or occurrence of disruption, slippage, mal position or herniation, associated with postoperative abnormal antireflux or defective valve as causes for reoperation ${ }^{6}$.

The objectives of this article are: a) to discuss the results of fundoplication and re-fundoplication in these cases, and b) to analyze in which clinical situation there is a room for gastrectomy after failed fundoplication.

METHOD

Our personal experience in 104 patients with failure after fundoplication and submitted to re-fundoplication or distal gastrectomy (RYDG) is presented. Also the experience in 50 cases with long segment Barrett's esophagus and in 60 obese submitted to fundoplication plus Roux-en-Y distal gastrectomy (RYDG) or laparoscopic resectional Roux-en-Y gastric bypass (LRGBP) alone, are included in order to compare the postoperative outcome after these procedures in terms of clinical( symptoms), endoscopic evaluation, manometry in order to evaluate lower esophageal sphincter (LES) pressure and $24 \mathrm{~h} \mathrm{pH}$ monitoring postoperative results.

\section{RESULTS}

\section{After re-fundoplication}

Table 1 shows our results observed in 104 patients with failure after initial fundoplication. Symptoms after surgical treatment for recurrent postoperative gastroesophageal reflux submitted to re-fundoplications alone vs. re-fundoplication combined with Roux-en-Y distal gastrectomy is shown. After re-do fundoplication, almost $20 \%$ of the patients continued having symptoms while symptoms were significantly less after re-fundoplication with Roux-en-Y distal gastrectomy (acid suppression/duodenal diversion surgery), in which only $5.5 \%$ of the patients presented reflux symptoms $(p<001)$. In Table 2 the results concerning to endoscopy, manometry, acid and bile reflux test before and after these procedures are shown. Recurrence of esophagitis after redo surgery alone was observed in $23.5 \%$ of the patients, which was significantly greater compared to the endoscopic findings of esophagitis observed in patients submitted to distal gastrectomy $(p<0.001)$. In patients with complicated Barrett's esophagus (with ulcer or strictures), endoscopic recurrence of erosive esophagitis was present in $100 \%$ of the patients operated upon with redo fundoplication alone; however, only $4.8 \%$ of patients with Roux-en-Y distal gastrectomy presented recurrence of esophagitis. Preoperative acid reflux was present in $94.7 \%$ of patients, in $93.6 \%$ after initial fundoplication and in $68.8 \%$ after redo-fundoplication. On the contrary, acid reflux was only present in $16.6 \%$ of patients submitted to distal gastrectomy $(p<0.001$, Table 2$)$. These results suggest that re-fundoplication is not a good option.
TABLE 1 - Symptoms after surgical treatment for recurrent postoperative gastroesophageal reflux comparing re-fundoplications vs. Roux-en-Y distal gastrectomy (RYDG) $(n=104)$

\begin{tabular}{|l|c|c|c|c|}
\hline \multirow{2}{*}{ Symptoms } & \multicolumn{2}{c}{ First operation } & \multicolumn{2}{c|}{ After re-operation } \\
\cline { 2 - 5 } & Preop & Posop & Re-fundoplication & RYDG \\
\hline Heartburn & $100 \%$ & $100 \%$ & $19.2 \%$ & $\begin{array}{c}5.5 \% \\
(\mathrm{p}<0.05)\end{array}$ \\
\hline Regurgitation & $86.7 \%$ & $80.6 \%$ & $11.5 \%$ & $\begin{array}{c}2.7 \% \\
(\mathrm{p}<0.05)\end{array}$ \\
\hline $\begin{array}{l}\text { Chest pain } \\
\text { Anemia }\end{array}$ & $29.5 \%$ & $28.5 \%$ & $3.8 \%$ & - \\
\hline Resp. symptoms & $6.1 \%$ & $9.1 \%$ & - & - \\
\hline
\end{tabular}

TABLE 2 - Endoscopy, manometry, acid and bile reflux before, after operation and after the reoperation $(n=104)$

\begin{tabular}{|l|c|c|c|c|} 
& \multicolumn{2}{c}{ First operation } & \multicolumn{2}{c|}{ After re-operation } \\
\cline { 2 - 5 } & Preop & Posop & Re-fundoplication & RYDG \\
\hline Erosive esophagitis & $100 \%$ & $83.4 \%$ & $23.5 \%$ & $7.7 \% *$ \\
\hline $\begin{array}{l}\text { Barrett with } \\
\text { esophagitis }\end{array}$ & & & & \\
\hline Ulcer/stricture & $100 \%$ & $100 \%$ & $100 \%$ & $4.8 \%$ * \\
\hline Incompetent LES & $82 \%$ & $56 \%$ & $53 \%$ & $32 \%$ \\
\hline Positive acid reflux & $95 \%$ & $94.3 \%$ & $69 \%$ & $11.1 \%$ * \\
\hline Biliary reflux & - & $57.6 \%$ & $40 \%$ & 0 \\
\hline
\end{tabular}

${ }^{*} \mathrm{p}<0.001$

\section{Barrett's esophagus}

Table 3 shows our experience in 50 patients with Barrett's esophagus submitted to laparoscopic fundoplication alone or combined with distal gastrectomy procedure. Symptoms recurrence, radiologic failures demonstrating positive reflux and inadequate antireflux valve, endoscopy demonstrating erosive esophagitis with Barrett's esophagus, persistence of positive reflux test or defective manometry after surgical treatment were significantly less frequent when combination of fundoplication plus distal gastrectomy was performed. This later operation presents low rate of major complications (Table 4).

TABLE 3 - Symptomatic and objective failures after laparoscopic surgery in patients with Barrett's esophagus submitted to fundoplication alone vs. combined fundoplication plus Roux-en-Y distal gastrectomy (RYDG) $(n=50)$

\begin{tabular}{|c|c|c|}
\hline & \multicolumn{2}{|c|}{ Long Segment Barrett's esophagus } \\
\hline & Fundoplication & Fundoplication+RYDG \\
\hline & $(n=22)$ & $(n=28)$ \\
\hline Symptoms recurrence & $36.5 \%$ & $3.7 \%$ \\
\hline Radiologic failure & $27.3 \%$ & $3.7 \%$ \\
\hline Endoscopic failure & $50 \%$ & $3.7 \%$ \\
\hline Positive acid reflux & $40.9 \%$ & $3.7 \%$ \\
\hline Incompetent LES & $31.8 \%$ & $21.4 \%$ \\
\hline
\end{tabular}

TABLE 4 - Early and late outcome after laparoscopic Roux-en-Y distal gastrectomy

\begin{tabular}{|l|c|c|}
\hline & Mean & Range \\
\hline Complications & $30.9 \%$ & $21-46 \%$ \\
\hline Re-operations & $11 \%$ & $9-12.5 \%$ \\
\hline Mortality & 0 & \\
\hline Hospital stay (days) & 6 & $1-33$ \\
\hline Satisfaction rate & $92 \%$ & $88-96 \%$ \\
\hline
\end{tabular}

References: $10,33,37,45,49$

\section{In obese patients}

In Table 5 and 6 the experience in 60 obese patients with Barrett's esophagus with BMI $<30 \mathrm{~kg} / \mathrm{m}^{2}$ or $>30 \mathrm{~kg} / \mathrm{m}^{2}$ is shown. The best results were observed after fundoplication Roux-en-Y distal gastrectomy (RYDG) or laparoscopic resectional Roux-en-Y gastric bypass (LRGBP) alone in LSBE patients in 
terms of symptoms, endoscopic findings, manometric and acid reflux tests.

TABLE 5 - Clinical results after fundoplication plus Roux-en-Y distal gastrectomy (RYDG) and laparoscopic resectional gastric bypass ( $L R G B P$ ) in patients with long segment Barrett's esophagus $(n=60)$

\begin{tabular}{|c|c|c|c|}
\hline \multicolumn{4}{|c|}{ LSBE } \\
\hline & Fundoplication+RYDG & LRGBP & \\
\hline \multicolumn{4}{|c|}{ Reflux Symptoms } \\
\hline Preop & 39 (100\%) & $21(100 \%)$ & \\
\hline Postop & $1(2.6 \%)$ & 0 & $(p=0.45)$ \\
\hline \multicolumn{4}{|c|}{ Erosive esophagitis } \\
\hline Preop & 39 (100\%) & $21(100 \%)$ & \\
\hline Postop & $1(2.6 \%)$ & 0 & $(p=0.45)$ \\
\hline \multicolumn{4}{|c|}{ Esophageal ulcer/stricture } \\
\hline Preop & $4(10.2 \%)$ & $6(28.6 \%)$ & \\
\hline Postop & 0 & 0 & \\
\hline \multicolumn{4}{|c|}{ Histology (presence of intestinal metaplasia) } \\
\hline Preop & $39(100 \%)$ & $21(100 \%)$ & \\
\hline Regression & $20(51.3 \%)$ & $13(61.9 \%)$ & $(p=0.35)$ \\
\hline
\end{tabular}

TABLE 6 - Manometry and 24h pH monitoring after Fundoplication plus RYDG and LRGBP in patients with long segment Barrett's esophagus $(n=60)$

\begin{tabular}{|c|c|c|}
\hline & \multicolumn{2}{|l|}{ LSBE } \\
\hline & Fundoplicatio+RYDG & LRGBP \\
\hline \multicolumn{3}{|c|}{ Hipotensive LES pressure } \\
\hline Preop & $39(100 \%)$ & $21(100 \%)$ \\
\hline Postop & $5(12,8 \%)$ & $21(100 \%)$ \\
\hline \multicolumn{3}{|c|}{ Abnormal acid reflux } \\
\hline Preop & $39(100 \%)$ & $21(100 \%)$ \\
\hline Postop & $1(2,6 \%)$ & $2(9,5 \%)$ \\
\hline
\end{tabular}

DISCUSSION

First of all, the decision to indicate reoperation after failed fundoplication is not easy. The decision to choose a remedial antireflux procedure is a challenging clinical problem which must be individualized depending on the clinical features of the patients, the characteristics and severity of symptoms, type of esophagitis, presence of ulcer, stricture, Barrett's esophagus, delayed gastric emptying, acid/bile reflux, the number of previous operations and the presence of obesity $10,12,24,27,35,38,44$. All of these factors must be taken into account in order to decide which surgery is the best option after a failed fundoplication.

To better understand this issue, the authors made a complete revision of the literature looking for the terms "failed fundoplication", "reoperation after fundoplication", "results after fundoplication", "surgery for Barrett's esophagus", "antireflux surgery in obese patients". For the data collection the searched bases were Pubmed, Medline, Cochrane library, Scopus, Google Scholar in order to have a complete vision of the problem. A total of 52 papers were reviewed to obtain the most accurate data regarding what the options are for treating a failed fundoplication.

The alternatives to treat failure are:

\section{Redo fundoplication}

This is the most frequent procedure used as a first approach. It is used in $89 \%$ of cases. It is a demanding procedure with a longer operative time, and it is more complex and difficult to perform compared to the first fundoplication. It can frequently present intra-operative complications such as bleeding, perforation, and spleen injury, which are more common compared to the initial fundoplication and increase after the first or second re-operation. The rate of intra-operative complications is $17-22 \%$ for the first re-operation and it reaches $36 \%$ during the second. The postoperative complications range from $15-27 \%$ and a long hospital stay may be required (6-58 days). The success rate after the first re-fundoplication is very variable ranging from 42 to $94 \%$ and decreases to $60 \%$ after the second re-fundoplication $3,7,20,23,25,28,34,35,45,46,51,52,53$. In addition, studies addressing long term outcomes have observed 27 to $41 \%$ of reflux recurrence with incomplete relief of symptoms in $12-50 \%$ of patients submitted to re-fundoplication. A very low satisfaction rate has been also reported with less than $50 \%$ of patients manifesting satisfaction after the re-operation ${ }^{49}$. Failure after the first redo-fundoplication is $12-20 \%$ and reaches $40 \%$ in cases submitted to a second redo. The worst results have been reported in obese or Barrett's esophagus patients ${ }^{7,20,25,41,49,50,51}$

Fundoplication combined with RYDG or LRGBP alone

Re-fundoplication plus RYDG is performed in only $12 \%$ of patients in North America. This is a more complex procedure because it involves two steps: first to perform re-fundoplication itself and second a distal gastrectomy. On the contrary, in patients with failure of initial fundoplication, or LRGBP alone without redo fundoplication avoids the performance of surgical dissection on an unfavorable surgical field with unclear anatomy due to the adhesions, fibrotic and distorted tissues. However, it is an incomplete procedure because it does not fix the inadequate anti-reflux barrier due the prior disrupted, slipped, asymmetric or herniated fundoplication. Therefore, it is possible to postulate that the combination of both procedures could be the best choice in order to avoid acid and bile reflux. The disadvantage of this alternative is the high rate of in-hospital or postoperative morbidity which can reach up to $67 \%$ after gastrectomy compared to only $20 \%$ after refundoplication $(p=0.007)^{10,12,31,33,37,45,47,49,51}$. On the other hand, the advantage of distal gastrectomy is relief of reflux symptoms after surgery, which reach nearly $89 \%$ compared to $50 \%$ after refundoplication $(\mathrm{p}=0.044)$. In selected patients with severe GERD, multiple previous fundoplications, other clinical situations such as Barrett's esophagus or obesity, we believe that gastrectomy is an acceptable treatment option with a significantly better long term outcome $\mathrm{e}^{15,30,35,40}$.

Concerning to the experience with long segment Barrett's esophagus (LSBE), the definitive treatment for patients with it remains controversial. For gastroenterologists, medical treatment with PPIs combined with ablation of Barrett's mucosa has demonstrated excellent long-term follow-up in terms of symptoms control and regression of metaplasia and even dysplasia $17,22,27,28,29,42,47,49,53$. Surgeons believe that laparoscopic anti-reflux surgery presents nil morbimortality and also very good results. The combination of fundoplication with ablation is a new way to explore ${ }^{27,31}$. However, long term follow after fundoplication alone in BE patients is unsatisfactory because acid and bile reflux persist in a high proportion of patients as we commented before $4,8,14,15,16,22$.

The goals of surgical treatment, are: a) controlling symptoms of gastroesophageal reflux disease; b) abolishing acid and duodenal reflux into the esophagus; $c$ ) preventing or eliminating the development of complications; d) preventing extension of or an increase in the length of the intestinal metaplasia; e) inducing regression of the intestinal metaplasia to the cardiac mucosa; and f) preventing progression to dysplasia, thereby inducing regression of low-grade dysplasia and avoiding the appearance of adenocarcinoma.

Experiences reported in patients with LSBE submitted to fundoplication have demonstrated unsatisfactory results at long term follow-up. Many authors have reported poor results due to a high rate of symptoms recurrence. Acid reflux persists at 8-10 years after surgery in a high proportion ranging between $7 \%-60 \%$ of patients. Duodenal reflux is present in $95 \%$ of them, and peptic ulcer, stricture, and erosive esophagitis appears in $15-30 \%$ late after surgery. Bowers and Oeschaleger ${ }^{4,42}$ have 
reported regression of intestinal metaplasia in 33\% and 55\% of patients respectively, and regression of low-grade dysplasia in $45 \%$ of patients with short segment Barrett's esophagus but not in patients with LSBE. Progression of the disease has been observed in almost $50 \%$ of patients with appearance of low-grade dysplasia in $6.0 \%$ and adenocarcinoma in $3.4 \% 9,17,18,28$.

Therefore, in patients with LSBE, the clinical results after fundoplication are not optimal. No long-lasting effect has been demonstrated and it does not prevent the appearance of dysplasia or adenocarcinoma. On the contrary, progression to dysplasia was observed in nearly $18 \%$ of cases at 5 -years follow-up ${ }^{9}$

Therefore RYDG is based on the following points: a) better control of severe gastroesophageal acid reflux and frequent duodenoesophageal reflux; b) better late results compared to the classic anti-reflux procedure in $\mathrm{BE} ; \mathrm{c}$ ) better healing of the esophageal damage produced by the injurious component of the refluxate. The authors have observed that the simple correction of the valve is not enough in many cases because it does not abolish the gastroesophageal reflux but only diminishes it. In patients who have BE and therefore have impaired esophageal clearance, few reflux episodes can maintain or even induce more damage. With the acid suppression/duodenal diversion procedure, the quality of the corrected valve is secondary, and the main goal is to avoid the reflux of injurious components of the refluxate instead of the refluxate itself which is almost always impossible.

Late results support this hypothesis and this surgical procedure as an alternative treatment in patients who have complicated BE or in patients who have long-segment BE.

Laparoscopic Roux-en-Y distal gastrectomy (RYDG) is an excellent alternative which has demostrated $91 \%$ clinical success for more than five years. This procedure has almost eliminated acid and duodenal reflux, and there has been no progression to dysplasia or adenocarcinoma. Moreover, in $60 \%$ of the patients with low-grade dysplasia, regression to non-dysplastic mucosa has occurred $8,15,16$.

The disadvantage of this operation is the high rate of complications and longer stay in hospital. However, no mortality has been reported after this technique and for us and many other authors the most important point is the very satisfactory results at long time follow-up. These results suggest that distal gastrectomy, in spite of having higher morbidity, is an acceptable treatment option with better long term outcome $25,31,33,37,47$ (Table 4).

\section{The experience in obese patients}

In obese patients with GERD or Barrett's esophagus there are two problems: a) reflux and its complications, and b) obesity.

In order to obtain an improvement of reflux and obesity, patients must be submitted to surgical procedures in order to accomplish both purposes: treat reflux (minimizing recurrences) and improve obesity index.

Then, the surgical options for treatment are:

\section{Fundoplication alone}

The results are not as good as in patients who are not severely obese and besides does not treat obesity. Morgenthal ${ }^{39}$ demonstrated that one of the important factors for recurrence of GERD after laparoscopic Nissen fundoplication is obesity, and a preoperative morbid obesity (BMI $\left.>35 \mathrm{~kg} / \mathrm{m}^{2}\right)$ was clearly associated with failure $(p=0.036)$. High rate of recurrence of gastroesophageal reflux has been demonstrated after fundoplication ${ }^{36-38}$. In our own experience, we reported almost $50 \%$ of reflux after fundoplication alone in obese patients ${ }^{10}$. Perez found that recurrence after fundoplication is correlated with increased $\mathrm{BMI}$; so, in normal weight the recurrence is $4.5 \%, 8 \%$ in overweight and $31 \%$ in obese patients ${ }^{45}$.
Combined procedures or gastric bypass with resection

In our experience, obese patients with $\mathrm{BMI}>30$ with $\mathrm{LSBE}$, two procedures have been employed: fundoplication+RYDG and LRGBP ${ }^{10}$. The main surgical differences between these two procedures are: a) addition of fundoplication in the former procedure; b) greater resection of the stomach (95\%), leaving a small gastric pouch of $30 \mathrm{ml}$ of capacity after LRGBP while the resection of distal stomach is approximately $40 \%$ after Fundolication+RYDG; c) the length of the alimentary Rouxen-Y limb is $60-70 \mathrm{~cm}$ after RYDG while after LRGBP it is closer to $130-150 \mathrm{~cm}$.

The indication of one procedure or other depends on the basal BMI and presence of co-morbidities. So, for non-diabetic or non-dislipidemic with BMI 30-35 we offer Fundoplication+RYDG. On the contrary, diabetic or dislipidemic patients with BMI more than 35 were indicated LRGBP in order to treat all these co-morbidities and reflux disease.

Despite the initial controversy or rejection of this idea by the majority of surgeons dedicated to this subject, in recent years it has been accepted due to the benefits of a long term follow-up. Others authors have confirmed a decrease in reflux symptoms, proton pump medication, acid reflux and complete regression of Barrett's esophagus after LRYGBP and for them, LRYGBP is the preferred surgery in morbidly obese patients with $B E^{12,19,30,32,37}$. This concept confirmed our idea suggesting this technique as an excellent strategy for these patients ${ }^{19}$.

Recent papers concluded that laparoscopic conversion of Nissen fundoplication to Roux-en-Y gastric bypass is a technically feasible and safe operation for recurrent gastroesophageal reflux disease in the morbidly obese with prior anti-reflux surgery, and in obese patients requiring surgical treatment for gastroesophageal reflux disease 1,12,19,30,31. In our opinion, laparoscopic Roux-en-Y gastric bypass is the best option for morbidly obese patients with Barrett's esophagus. In addition, in a recent publication, Altieri ${ }^{1}$ concluded that Roux-en-Y gastric bypass is associated with a decreased incidence of GERD and it is the procedure of choice for obese with GERD and for patients with Barrett's esophagus $2,11,26,28,37,39,40,4546,52$.

\section{CONCLUSION}

Patients who have BE have anatomical and physiological foregut abnormalities which cannot be improved with antireflux surgery or reoperations. However, laparoscopic refundoplications continue to be the most common revisional surgery after failed fundoplication, but the late results are poor and with a high recurrence rate. Barrett's patients also have a high rate of recurrence and worse so after re-fundoplication. There are patients that have been unnecessarily submitted to 1, 2 or even 3 re-operations. In these cases, fundoplication plus acid suppression/duodenal diversion techniques with Roux-en-Y distal gastrectomy provides better control of the disease. Therefore, there is a place for this procedure in patients with failure after initial fundoplication because it is adequate, safe and reliable as a first line therapy.

In obese with gastroesophageal reflux disease and Barrett'esophagus an acid suppression/bile diversion procedure similar to gastric bypass has been recommended as an effective combined bariatric and anti-reflux surgical procedure, achieving endoscopic and histologic regression to normal mucosa in a substantial number of patients.

Despite its higher morbidity, this procedure represents an important addition to the surgical armamentarium. For us, it is the first option in these three clinical situations. 
REFERENCES

1. Altieri MS, Pryor AD. Gastroesophageal reflux disease after bariatric procedure. Surg Clin North Am. 2015;95:579-91

2. Andrew B, Alley JB, Aguilar CE, Fanelli RD. Barrett's esophagus before and after Roux-en-Y gastric bypass for severe obesity. Surg Endosc. 2018:32:930-936.

3. AwaisO,LuketichJD, ReddyN,BiancoV,LevyRM,SchuchertMJ,GoodingWE, CristLR, LandreneauRJ,PennathurA. Roux-en-Ynearesophagojejunostomy for failed antireflux operations: outcomes in more than 100 patients. Ann Thorac Surg. 2014;98:1905-11.

4. Bowers S, matterS, Smith CD, Waring JP, HunterJG. Clinical and histological follow-up after antireflux surgery for Barrett's esophagus. J. gastroentest surg. 2002:532-39

5. Braghetto I, Korn O, Csendes A, Valladares H, Davanzo C, Debandi A Radiologic and endoscopic characteristics of laparoscopic antireflux wrap: correlation with outcome. Int Surg. 2012;97:189-97

6. Braghetto I, Csendes A, Korn O, Burdiles P, Valladares H, Cortés C, Deband A Anatomical deformities after laparoscopic antireflux surgery. Int Surg 2004:89:227-35

7. Braghetto I, Csendes A, Burdiles P, Botero F, Korn O Results of surgical treatment for recurrent postoperative gastroesophageal reflux Dis Esophagus. 2002:15:315-22.

8. Braghettol, KornO, Valladares H, DebandiA, DíazJC, BrunetL. Laparoscopic surgical treatment for patients with short- and long-segment Barrett's esophagus: which technique in which patient? Int Surg. 2011;96:95-103

9. Braghetto I, Csendes A, Smok G, Gradiz M, Mariani V, Compan A, Guerra JF Burdiles $\mathrm{P}$, Korn $\mathrm{O}$. Histological inflammatory changes after surgery at the epithelium of the distal esophagus in patients with Barrett's esophagus: a comparison of two surgical procedures. Dis Esophagus. 2004;17:235-42.

10. Braghetto I, Korn O, Csendes A, Gutiérrez L, Valladares $H$, Chacon M. Laparoscopictreatmentofobesepatientswithgastroesophagealrefluxdisease and Barrett's esophagus: a prospective study. Obes Surg. 2012;22:764-72

11. Braghettol,CsendesA.Patients Having BariatricSurgery:SurgicalOptionsin MorbidlyObesePatientswithBarrett'sEsophagus.ObesSurg.2016;26:1622-6.

12. Coakley KM, Groene SA, Colavita PD, Prasad T, Stefanidis D, Lincourt AE Augenstein VA, Gersin K, Heniford BT. Roux-En-Y gastric bypass following failed fundoplication. Surg Endosc. 2018; 23. doi: 10.1007/s00464-0186072-9. [Epub ahead of print]

13. Cobey F, Oelschlager B. Complete regression of Barrett's esophagus after Roux-en-Y gastric bypass. Obes Surg. 2005;15:710-2

14. Csendes A. Surgical treatment of Barrett's esophagus: 1980-2003. World J Surg. 2004;28:225-31

15. Csendes A, Burdiles P, Braghetto I, Korn O, Díaz JC, Rojas J. Early and late results of the acid suppression and duodenal diversion operation in patients with barrett's esophagus: analysis of 210 cases. World J Surg 2002;26:566-76.

16. Csendes A, Braghetto I, Burdiles P, Korn O.Roux-en-Y long limb diversion as the first option for patients who have Barrett's esophagus. Chest Surg Clin N Am. 2002:12:157-84

17. CsendesA, Braghetol,BurdilesP,SmokG,HenriquezA,ParadaF.Regression ofintestinalmetaplasiatocardiacorfundicmucosain patientswith Barrett's esophagus submitted to vagotomy, partial gastrectomy and duodenal diversion. A prospective study of 78 patients with more than 5 years of follow up. Surgery. 2006;139:46-53.

18. CsendesA, BurdilesP, Braghettol,KornO.Adenocarcinomaappearingvery late after antireflux surgery for Barrett's esophagus: long-term follow-up review of the literature, and addition of six patients. J Gastrointest Surg. 2004:8:434-41

19. Csendes A. Burgos AM, Smok G, Burdiles P, Henriquez A Effect of gastric bypass on Barrett's esophagus and intestinal metaplasia of the cardia in patients with morbid obesity. J.Gastrointest Surg 2006;10:259

20. DallemagneB,ArenasSanchezM,FrancartD, PerrettaS, WeertsJ,Markiewicz $\mathrm{S}$, Jehaes $\mathrm{C}$. Long-term results after laparoscopic reoperation for failed antireflux procedures. Br J Surg. 2011;98:1581-7.

21. Desai K, Soper NJ, Frisella MM, Quasebarth MA, Dunnegan DL, Brunt LM. Efficacy of laparoscopic antireflux surgery in patients with Barrett's esophagus. Am J. Surg. 2003:186:652.

22. dos Santos RS, Bizekis C, Ebright M, DeSimone M, Daly BD, Fernando HC Radiofrequency ablation for Barrett's esophagus and low-grade dysplasia in combination with an antireflux procedure: a new paradigm. J Thorac Cardiovasc Surg. 2010;139:713-6.

23. Farrell TM, Smith CD, Metreveli RE, Johnson AB, Galloway KD, Hunter JG. Fundoplication provides effective and durable symptom relief in patients with Barrett's esophagus. Am. J. Surg. 1999:178:18-21

24. Friedenberg FK, Xanthopoulos M, Foster GD, Richter JE. The association betweengastroesophageal refluxdiseaseand obesity.Am.J.Gastroenterol. 2008:103:2111-2122

25. Furnée EJ, Draaisma WA, Broeders IA, Gooszen HG. Surgical reintervention after failed antireflux surgery: a systematic review of the literature. J Gastrointest Surg. 2009;138:1539-49.
26. Grover BT, Kothari SN. Reoperative antireflux surgery. Surg Clin North Am. 2015;95:629-40.

27. GurskyRR, PetersJH, Hagen JA, DeMessterTR, Barrett's esophagus can and does regress after antireflux surgery: a study of prevalence and predictive factors. J Am. Coll.Surg 2003;196:706-13

28. GutschowCA,SchröderW,BludauM,VallböhmerD,PrenzelKL,Bollschweiler E, Hölscher AH. Barrett's esophagus: re-fundoplication. Zentralbl Chir. 2011:136:249-55

29. HorganS, PohID, BogettiD, EubanksT, PellegriniC. Failedantirefluxsurgery: what have we learned from reoperations? Arch Surg. 1999;134:809-5

30. Houghton SG, Romero Y, Sarr MG. Effect of Roux-en-Y gastric bypass in obesepatientswithBarrett'sesophagus:attempstoliminateduodenogastric reflux.Surg Obes Relat Dis 2008:4:1-4

31. Hubbard N, Velanovich V. Endoscopic endoluminal radiofrequency ablation of Barrett's esophagus in patients with fundoplications. Surg Endosc. 2007:21:625-8

32. Kellogg TA, Andrade R, Maddaus M, Slusarek B, Buchwald H, Ikramuddin S.Anatomic findings and outcomes afterantirefluxproceduresinmorbidly obese patients undergoing laparoscopic conversion to Roux-en-Y gastric bypass. Surg Obes Relat Dis. 2007;3:57; discussion 58-9

33. Kim M, Navarro F, Eruchalu CN, Augenstein VA, Heniford BT, Stefanidis D. Minimally invasive Roux-en-Y gastric bypass for fundoplication failure offersexcellentgastroesophageal refluxcontrol.AmSurg.2014;80:696-703.

34. KindelTL, OleynikovD. Thimprovementofgastroesophageal refluxdisease and Barrett'sesophagusafterbariatricsurgeryObes.Surg2016;26;718-720

35. Makdisi G, Nichols FC 3rd, Cassivi SD, Wigle DA, Shen KR, Allen MS Deschamps C. Laparoscopic repair for failed antireflux procedures. Ann Thorac Surg. 2014;98:1261-6

36. Mejía-Rivas M. Herrera-López A, Hernández-Calleros J, Herrera MF, Valdovinos MA. Gastroesophageal reflux disease in morbid obesity: the effect of Roux-en-Y gastric bypass. Obes Surg 2008:18:1217-24.

37. Mendes-filho, Antônio Moreira et al. Fundoplication conversion in rouxen-y gastric bypass for control of obesity and gastroesophageal reflux: systematic review. ABCD, Arq. Bras. Cir. Dig. 2017;30:279-282.

38. Mittal SK, Légner A, Tsuboi K, Juhasz A, Bathla L, Lee TH. Roux-en-Y reconstruction is superior to redo fundoplication in a subset of patients with failed antireflux surgery. Surg Endosc. 2013 ;27:927-35

39. Morgenthal CB, Lin E, Shane MD, Hunter JG, Smith CD Who will fail laparoscopic Nissen fundoplication? Preoperative prediction oflong-term outcomes. Surg Endosc. 2007;21:1978-84.

40. Nadaleto BF, Herbella FA, Patti MG. Gastroesophageal reflux disease in the obese: Pathophysiology and treatment. Surgery. 2015; 5

41. Obeid NR, Altieri MS, Yang J, Park J, Price K, Bates A, Pryor AD. Patterns of reoperation after failed fundoplication: an analysis of 9462 patients. Surg Endosc 2017

42. O'Connell K, Velanovich V. Effects of Nissen fundoplication on endoscopic endoluminal radiofrequencyablation ofBarrett'sesophagus. Surg Endosc. 2011;25:830-4

43. Oeschlager BK, Barrera M, Chang L. Oleynokov D, Pellgrini C. Clinical and pathological response of Barrett's esophagus to laparoscopic antireflux surgery. Ann Surg 2003;238:456-66

44. Ohnmacht GA, Deschamps C, Cassivi SD, Nichols FC 3rd, Allen MS, Schleck $C D$, Pairolero PC. Failed antireflux surgery: results after reoperation. Ann Thorac Surg. 2006:81:2050-3,

45. PerezAR, MoncureAC, RattnerDW.Obesity adversely affects the outcome of antireflux operations. Surg Endosc 2002;15:986-9

46. Raftopoulos I, Awais O, Courcoulas AP, Luketich JD Laparoscopic gastric bypassafterantirefluxsurgeryforthetreatmentofgastroesophageal reflux in morbidly obese patients: initial experience. Obes Surg. 2004;14:1373-80.

47. Shaheen NJ, Falk GE, lyer PG, MD, Gerson L. ACG Clinical Guideline: Diagnosis and Management of Barrett's Esophagus. Am J. gastroenterol 2016:111:30-50

48. D, Navarro F, Augenstein VA, Gersin KS, Heniford BT. Laparoscopic fundoplication takedown with conversion to Roux-en-Y gastric bypass leads to excellent reflux control and quality of life after fundoplication failure. Surg Endosc. 2012;26:3521-7.

49. Wani S, Rubenstein JH, Vieth M, Bergman J. Diagnosis and Management of Low-Grade Dysplasia in Barrett's Esophagus: Expert Review From the Clinical Practice Updates Committee of the American Gastroenterological Association. Gastroenterology 2016;151:822-835.

50. Williams VA, Watson TJ, Gellersen O, Feuerlein S, Molena D, Sillin LF, Jones C, Peters JH. Gastrectomy as a remedial operation forfailed fundoplication. J Gastrointest Surg. 2007:11:29-35

51. Wilshire CL, Louie BE, Shultz D, Jutric Z, Farivar AS, Aye RW. Clinical Outcomes of Reoperation for Failed Antireflux Operations. Ann Thorac Surg. 2016:101:1290-6

52. Yamamoto SR, Hoshino M, Nandipati KC, Lee TH, Mittal SK. Long-term outcomes of reintervention for failed fundoplication: redo fundoplication versus Roux-en-Y reconstruction. Surg Endosc. 2014;28:42-8.

53. Zaninotto G, Cassaro M, Pennelli G, Bataglia G, Farinatti F, Ceolin M. Brrett's epithelium after antireflux surgery. J, Gastrointestinal Surg, 2005;9:1253-6 